\title{
Development and Promotion of the Reversible Airflow Flatbed Dryer in the Philippines
}

\author{
Caesar Joventino M. Tado ${ }^{1}$, Dexter P. Ona ${ }^{1}$, John Eric O. Abon ${ }^{1}$, \\ Eden C. Gagelonia', Nguyen Thanh Nghi ${ }^{2}$, and Le Quang Vinh ${ }^{2}$ \\ ${ }^{1}$ Rice Engineering and Mechanization Division, Philippine Rice Research Institute, \\ Maligaya, Science City of Muñoz, Nueva Ecija, Philippines. \\ ${ }^{2}$ Nong Lam University, Ho Chi Minh City, Vietnam
}

\begin{abstract}
A flatbed dryer with a reversible airflow was introduced in the Philippines through a collaborative project between Nong Lam University of Vietnam and the Philippine Rice Research Institute (PhilRice). In this design, airflow is reversed at some point during the drying period to achieve uniform drying without mixing the grain.

An 8-ton capacity dryer was constructed at PhilRice Central Experiment Station in Nueva Ecija to evaluate its performance and adaptability under Philippine conditions. Appropriate and locally available materials were used in the construction of the pilot unit. Nine (9) additional dryers were then constructed at PhilRice stations (Nueva Ecija, Isabela, Negros, Agusan, Central Mindanao University, and Midsayap) that served as pilot units for technology promotion in their respective areas of coverage. Performance of the dryer was evaluated in terms of the following parameters: (1) drying; (2) quality of dried grains; and (3) economic analysis of using the dryer. The performance evaluation was conducted in three drying batches of newly harvested rice seeds.

Paddy dried with the reversible airflow flatbed dryer at full load capacity has a uniform moisture content with one percent (1\%) moisture gradient at different layers of the grain mass along the depth and across the drying bin. The drying rate was $1 \%$ moisture reduction per hour.

The drying cost of using the reversible dryer is $\mathrm{PhP} 0.74$ per $\mathrm{kg}$ which is lower than the prevailing mechanical drying cost of $\mathrm{PhP} 1.13$ per $\mathrm{kg}$. It has a payback period of 2.5 years and break-even point of 53.0 batches/year. To date, eight (8) privately-owned units have already been constructed and fully operational in the provinces of Nueva Ecija, Quirino, and Bukidnon, with PhilRice receiving inquiries from interested individuals here and abroad regarding the technology.
\end{abstract}

Keywords: reversible airflow flatbed dryer, drying rate, moisture gradient

Correspondence: C.J.M. Tado Address: Rice Engineering and Mechanization Division, Philippine Rice Research Institute, Maligaya, Science City of Muñoz, Nueva Ecija, Philippines. Telephone: (044)456-0285 E-mail:cjmtado@yahoo.com.

DOI: 10.32945/atr3717.2015 


\section{INTRODUCTION}

The recent spike in world rice prices showed the vulnerability of countries such as the Philippines which depend on imports for its food security, to the volatility of the world rice market. In many countries of Asia, increase in rice production has been traditionally attained by increasing the area devoted to rice. In the Philippines, however, we can no longer afford this luxury, as the physical area planted to rice has already reached its upper limit. The country's quest for self sufficiency in rice should therefore be done in a two-pronged approach: increasing productivity of our ricelands, and reducing postharvest losses. Approximately $15 \%$ of our rice production is lost in postharvest handling and processing. Thirty percent of the total postharvest losses is lost in drying (BPRE, 2003, as cited by PCARRD, 2009). Since the rice grain quality starts to deteriorate 24 hours after harvest if left undried, farmers need ready access to dryers.

Given the above scenario, the introduction of mechanical dryers in the Philippines is a must. Many recirculating mechanical dryers were put up in the country as part of the government's intervention to the prevalent postharvest problem in the countryside. However, many of these units are now idle due to very high operating costs and lack of technical expertise on the parts of the farmers/cooperatives to maintain these postharvest facilities. The Department of Agriculture, through the Philippine Center for Postharvest Development and Mechanization (PhilMech) has also embarked on distributing the 6-ton flatbed dryers to selected cooperatives and irrigators' associations, as one of the interventions in reducing postharvest losses of paddy (Gagelonia, et al., 2013). However, issues like difficulty in mixing during drying are always raised by the users. Mixing can be eliminated by reversing the direction of the drying air at some point during the drying period. A reversible airflow grain dryer was developed in Leyte, Philippines in the 1990s (Kuizon, 1995). The air is blown at the center into the plenum chamber underneath the drying bin, thus increasing the bed height level, and making it more difficult for manual loading.

The reversible airflow flatbed dryer (e.i. reversible dryer) which is now being extensively used in the Mekong Delta of Vietnam is a dryer which also uses farm biomass such as rice hull for fuel (Hien, 2010). In this configuration, the air is blown at the side duct of the drying bin, so that the bed height level remains low.As the direction of the drying front is reversed at some point during dying, mixing of the grains in the drying bin is now 
Development and Promotion of the Reversible Airflow Flatbed Dryer

eliminated. This type of dryer therefore presents a bright potential of being adopted in the country. Thus, this study wasconducted in order to introduce and promote the technology in the Philippines.

\section{OBJECTIVES}

The general objective was to introduce the Vietnamese reversible drying technology to the Philippines and adapt it to local conditions. Specific objectives were as follows:

1. To build the reversible dryer and evaluate its performance;

2. To modify the design based on the results of evaluation to suit local field conditions; and

3. To promote the technology in the major rice producing provinces of the country.

\section{METHODOLOGY}

\section{Observation Tour}

As an initial activity, an observation tour by key officials of the Department of Agriculture, PhilRice, and PhilMech to observe the reversible dryer in operation in Vietnam was organized. The main objective of the tour was for tour participants to familiarize themselves with the technology and to determine its possibility of being adopted in the Philippines. Travel expenses of the tour participants were shouldered by the International Rice Research Institute (IRRI).

\section{Dispatch of Vietnamese Experts to PhilRice}

The transfer of the reversible drying technology from Vietnam to the Philippines included the dispatch of two (2) Vietnamese experts to PhilRice to provide technical assistance to the PhilRice team in constructing the dryer as well as in the technical evaluation of the dryer. The plan was to invite one (1) PhD student and one (MS) student who would take their graduate studies at a reputable higher education institution in the country. The cost of their stay in the Philippines was borne by PhilRice. 
Description of the Reversible Airflow Flatbed Dryer

The reversible dryer (Figure 1) adopted in the Philippines is the product of the collaborative project on transferring the reversible drying technology of Nong Lam University to PhilRice. It has three main components, namely: the furnace, the blower assembly, and the drying bin. The dryer has a capacity of 8 tons of paddy per batch. The fan used is an axial-flow type having a diameter of $900 \mathrm{~mm}$ (Figure 2). This is powered by a 22-25 hp diesel engine or an $11 \mathrm{~kW}$ electric motor. The rice hull furnace is the second generation furnace which has incorporated a cylindrical combustion chamber for better separation of the fly ash. The drying bin is a flatbed-type with side-duct plenum and perforated screen flooring. During the reversal of the airflow, the top of the drying bin is covered, the trap door of the air-reversal device is opened to allow the air to flow from the top of the drying bin in the downward direction, ultimately exiting at the side of the plenum below. The dryer was constructed at the Central Experiment Station of PhilRice (PhilRice CES) by PhilRice engineers, in collaboration with the technical experts from Vietnam.

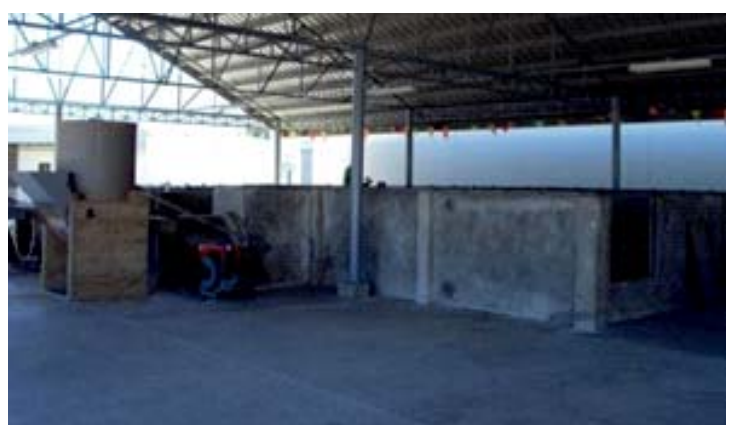

Figure 1. The reversible airflow flatbed dryer.

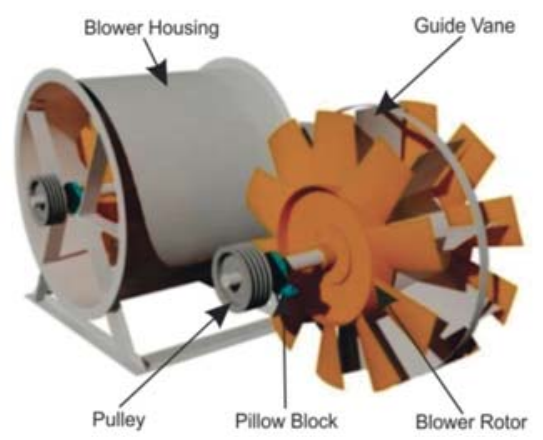

Figure 2. Two-stage axial flow fan used in the reversible dryer. 
Development and Promotion of the Reversible Airflow Flatbed Dryer

\section{Principle of Operation}

Drying material is manually loaded into the drying bin with a depth of 50 to $60 \mathrm{~cm}$. Heated air is produced by the furnace and sucked by the dryer fan. The drying air blown into the drying bin is a mixture of the hot air from the furnace and ambient air. The drying air temperatures of 40 to $43^{\circ} \mathrm{C}$ are used for drying of seed grains. Grains for milling purposes can be dried at higher temperatures. During the drying process, rice husk and ashes are manually fed and discharged, respectively. The drying process involves two periods, namely:

The upward drying period. In this period (Figure 3a), the fan blows the heated air into the air-reversal chamber which is connected to the lower side-plenum chamber, and then to the plenum chamber under the floor. The air then goes through layers of grain mass, bringing moisture vaporized from grains, and exits on top of the grain mass. This phase continues until the moisture content of the second layer of the 3-layer grain mass is around $2.5-4.0 \%$ higher than desired moisture level, which is about two-thirds (2/3) of total drying time of the batch (Hien et al., 2003).

The downward drying period. During this period (Figure $3 \mathrm{~b}$ ), the cover sheet is used to cover the whole drying bin and must be tightly fastened. The air-reversal chamber is then set so that the heated air enters the upper side-plenum chamber, turns toward the space between the cover sheet and top of grain mass, goes through upper and lower layers of grain mass, and exits at openings on the side of the lower side-plenum chamber. Drying is then continued until the desired moisture content is reached.

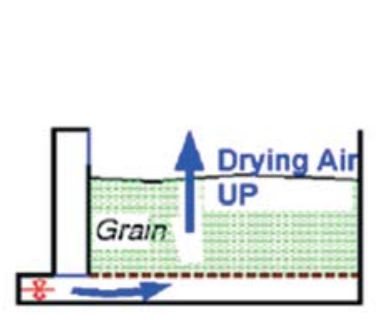

(a)

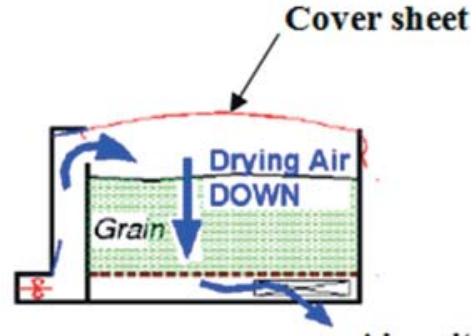

(b)

Air exit windows

Figure 3. Principle of operation of the reversible dryer. 


\section{Technical Evaluation}

After constructing the dryer, the unit was subjected to a series of laboratory tests to determine its critical operating parameters and to finetune the unit. Afterwards, a series of actual drying tests at full capacity was conducted to determine its field performance. Aspects of the laboratory and field evaluation were used by the Vietnamese counterparts as their research topics for their graduate studies at the nearby Central Luzon State University (CLSU).

The dryer was tested based on the Philippine Agricultural Engineering Standards (PAES 202:2000). Right after loading the grain sample, checking the initial distribution of air (Figure 4) and installing the different instruments were carried out, after which, the drying operation was started. In these experiments, temperature and relative humidity of ambient, drying, and exhaust air were measured with an interval of 30 minutes during the drying process. Since the drying bed area of the dryer was rather large, it was necessary to collect data of sample moisture content (MC) and air velocity at several points in the drying bed. From the second drying period onwards (after covering the canvas sheet to reverse direction of the drying airflow), grain MC was only taken when the drying process was finished, because unfastening and reinstalling of cover sheet as well as getting samples would take much time. Drying operation was terminated when the desired final MC of grain was reached. At the end of the drying process, the fan was allowed to run for 30-45 minutes for proper tempering of the paddy and prevent grain fissures. Milling operations were done on the following day.

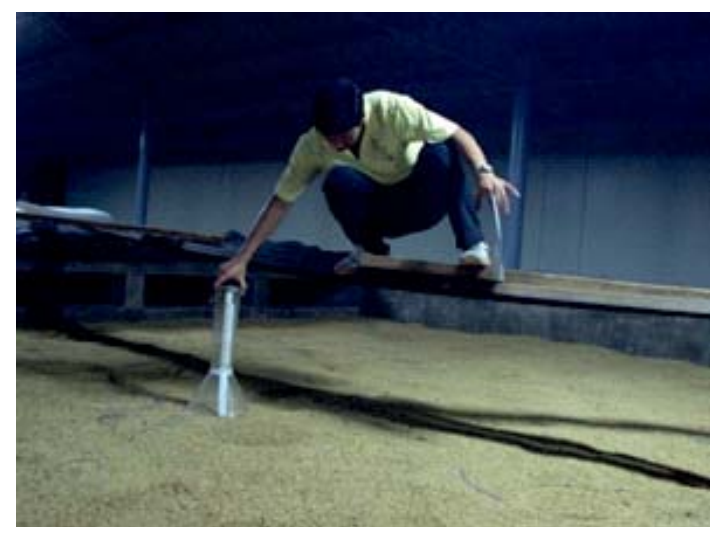

Figure 4. Checking the air distribution. 
Development and Promotion of the Reversible Airflow Flatbed Dryer

Economic Analysis

An economic analyis of the reversible dryer was conducted in collaboration with the Socio-economics Division of PhilRice to guide the adoptors of the technology on the profitability of its operation.In estimating the cost of drying, the maximum drying capacity of the dryer was used to calculate related parameters. Estimation of the drying cost needs general assumptions which were based on actual drying operations at the PhilRice CES. Economic indicators were payback period and internal rate of return (IRR). The payback period in years is the time required to recoup the investment and the IRR is the interest rate that makes the net present value of all cash flow equal to zero.

\section{Technology Promotion Strategies}

Additional 12 units of reversible dryers were constructed in 6 PhilRice stations. These units serve as demonstration units for all those who are interested in the technology. The dryer is also included among the technologies being showcased during the regular field days conducted by the PhilRice stations in collaboration with the Department of Agriculture (DA) and LGU personnel. Technical assistance were provided by PhilRice to those who are interested in constructing the dryer. Furthermore, the dryer was included among the postharvest technologies being promoted by IRRI and PhilRice through a collaborative project "Addressing the Pre-and Postharvest Challenges in the Rice Supply Chain."

\section{Training and Technical Assistance to Technology Adaptors}

Farmers and other stakeholders who were interested on the reversible dryer technology were provided hands-on training on the operation and maintenance of the dryer. In addition, several batches of similar training courses were conducted for agricultural extension workers in Bohol, Agusan and Bicol through the collaborative postharvest project with IRRI. Several operators and owners of the conventional flatbed dryer also benefited from the above training courses. 


\section{RESULTS AND DISCUSSION}

\section{Performance Test of Blower}

Performance test of the blower was conducted at the Rice Engineering and Mechanization Division of PhilRice using a locally-fabricated fan test duct (Figures 5 and 6). The aim was to measure fan parameters such as air rate, power consumption, and fan efficiency. The performance of the blower is shown in Table 1.

Table 1. Performance of the reversible dryer blower.

\begin{tabular}{|c|c|c|c|c|c|c|c|c|c|}
\hline $\begin{array}{l}\text { STATIC } \\
\text { PRESS., } \\
\mathrm{mm} \mathrm{H}_{2} \mathrm{O}\end{array}$ & $\begin{array}{c}\text { AIR } \\
\text { VOLUME } \\
\mathrm{m}^{3} / \mathrm{s}\end{array}$ & $\begin{array}{c}\text { STATIC } \\
\text { AIR Eff., } \\
\%\end{array}$ & $\begin{array}{c}\text { OVERALL } \\
\text { Eff., } \\
\% \\
\end{array}$ & $\begin{array}{c}\text { MOTOR } \\
\text { POWER, } \\
\text { kW }\end{array}$ & $\begin{array}{c}\text { MOTOR } \\
\text { POWER, } \\
\text { hp }\end{array}$ & $\begin{array}{l}\text { STATIC } \\
\text { PRESS., } \\
\mathrm{mmH}_{2} \mathrm{O}\end{array}$ & $\begin{array}{c}\text { AIR } \\
\text { VOLUME, } \\
\mathrm{m}^{3} / \mathrm{s}\end{array}$ & $\begin{array}{c}\text { MOTOR } \\
\text { POWER, } \\
\text { kW }\end{array}$ & $\begin{array}{c}\text { MOTOR } \\
\text { POWER, } \\
\text { hp }\end{array}$ \\
\hline 64.60 & 10.65 & 53.64 & 67.45 & 13.77 & 18.46 & 36.40 & 7.99 & 5.82 & 7.80 \\
\hline 54.40 & 10.90 & 47.64 & 62.91 & 13.39 & 17.95 & 30.60 & 8.18 & 5.66 & 7.59 \\
\hline 38.60 & 10.68 & 35.77 & 51.30 & 12.49 & 16.74 & 21.70 & 8.02 & 5.28 & 7.08 \\
\hline 26.10 & 10.72 & 25.72 & 42.34 & 11.85 & 15.88 & 14.70 & 8.04 & 5.01 & 6.72 \\
\hline 19.30 & 10.51 & 18.27 & 33.57 & 12.10 & 16.22 & 10.90 & 7.89 & 5.12 & 6.86 \\
\hline \multicolumn{10}{|c|}{ Fan-shaft speed, $\mathrm{n}=1,332 \mathrm{rpm}^{*}$} \\
\hline
\end{tabular}

"The mean speed of blower shaft measured when testing.

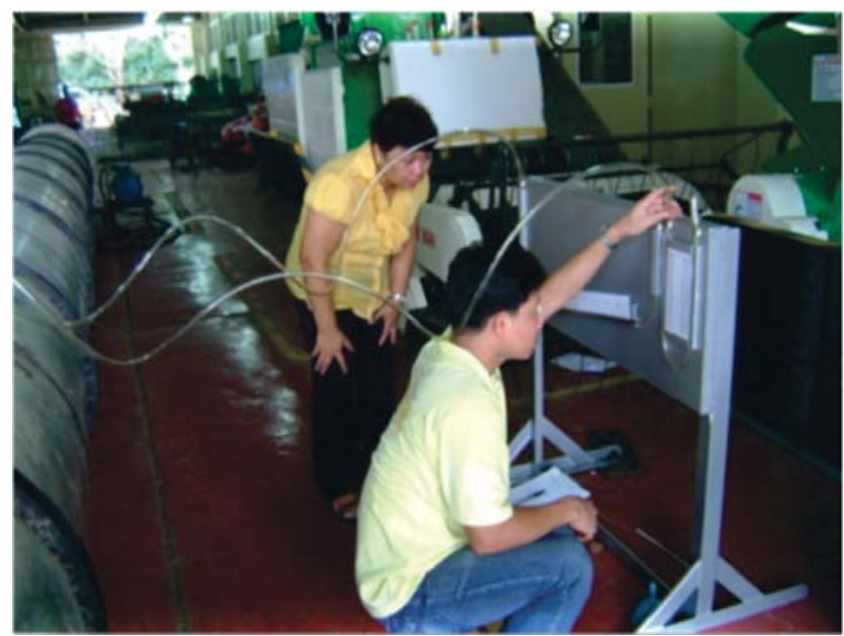

Figure 5. Static pressure measurement using an inclined manometer. 


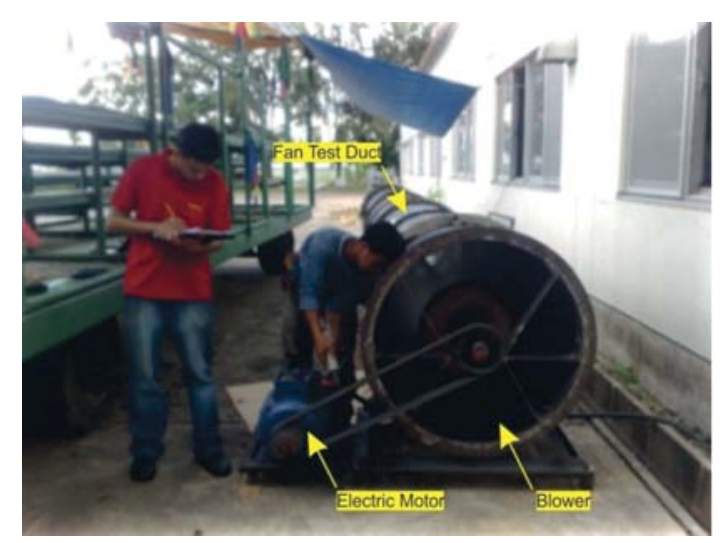

Figure 6. Measurement of power consumption of the blower using a power meter.

The blower was able to produce enough required air volume even as the speed was converted to $1,000 \mathrm{rpm}$. An air flow rate of about $8.0 \mathrm{~m}^{3} / \mathrm{s}$ at a static pressure of $36 \mathrm{mmH}_{2} \mathrm{O}$ was produced by the blower, which met the requirements for air volume in the dryer.

\section{Performance Test of Dryer}

Dryer performance was evaluated by drying wet paddy at full-load capacity to determine the drying rate, air velocity, moisture content gradient, fuel/power consumption, and rice hull consumption. Test results are shown in Table 2.

Table 2. Performance test results of the reversible dryer

\begin{tabular}{ll}
\hline \multicolumn{1}{c}{ Parameters } & Values \\
\hline Mean Drying Rate (\%/h) & 0.88 \\
Mean MC Gradient (\%) & 1.03 \\
Drying Efficiency (\%) & 44.01 \\
Cracked Grains (\%) & 0.53 \\
Head Rice Recovery (\%) & 60.34 \\
Germination Rate (\%) & 91.53 \\
Drying Cost (PhP/kg) & 0.74 \\
Payback Period (yr) at 120 batches/yr & 2.42 \\
\hline
\end{tabular}


Based on the data gathered, the reversible dryer had a mean drying efficiency of $44.01 \%$. The drying curve and the linear regression equation of the dryer were derived and are shown in Figure 7. The drying rate was not so fast and is deemed suitable for drying seeds. There was no observed soot or blackening of the grains, indicating that the cylindrical combustion chamber with fly ash separator has performed very well.

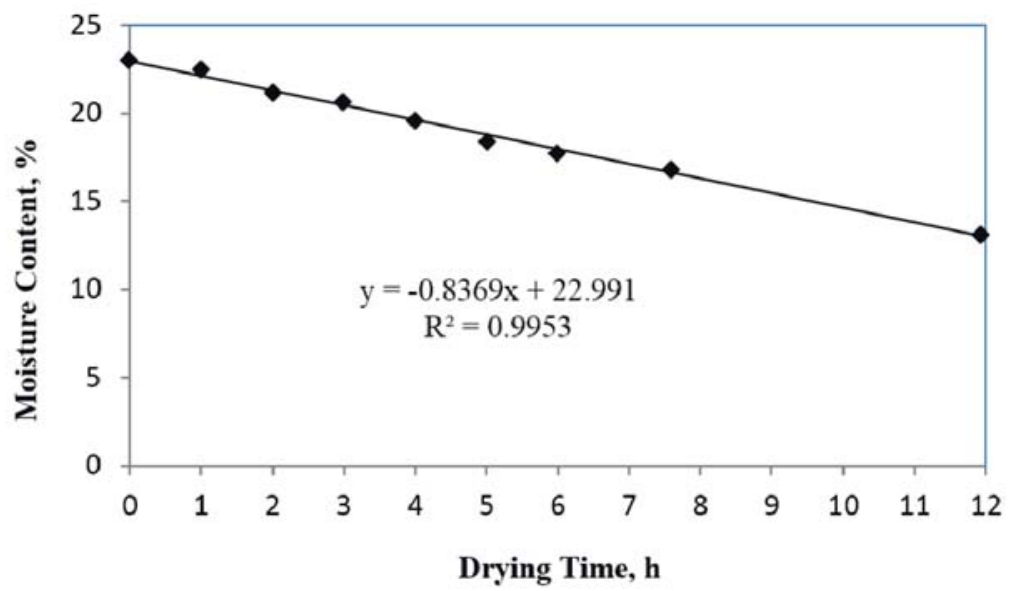

Figure 7. Drying curve of the reversible dryer.

\section{Economic analysis}

The cost of drying is dependent on investment cost and annual drying capacity. With an annual use of 120 drying batches/yr, the drying cost of the reversible dryer was PhP0.735/kg of dried paddy which was cheaper than the prevailing mechanical drying cost of $\mathrm{PhP} 1.13 / \mathrm{kg}$ of dried paddy in the Philippines (Vinh, 2011).

Payback period for the reversible dryer was computed to be 2.42 years, with break-even point of 53.0 batches/yr (Figure 8). It has an internal rate of return of $33.14 \%$. 
Development and Promotion of the Reversible Airflow Flatbed Dryer

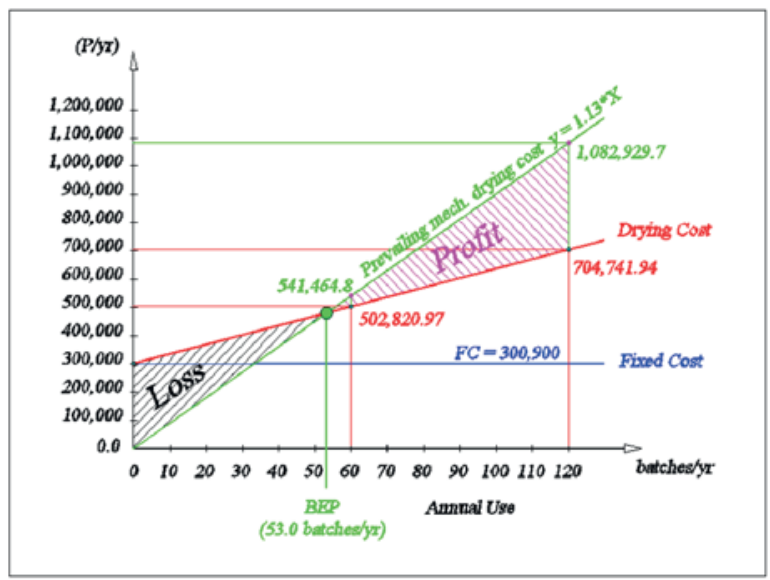

Figure 8. Determining the break-even point of using the reversible dryer.

\section{Technology Promotion and Knowledge Sharing}

As a result of the information campaign conducted on the technology, a number of private individuals and farmers' groups have already adopted the technology, as shown in Table 3. After the dryer was installed, operators were trained about its operation, maintenance, and troubleshooting. During the training, the operators and the dryer owners were provided with operator's manuals (Figures 9 and 10).

Furthermore, the reversible drying technology is being promoted to farmers, traders, and cooperatives through conferences, workshops,field days, and training courses held at the PhilRice stations.Knowledge sharing madethe stakeholders realize the importance of mechanical drying technology.

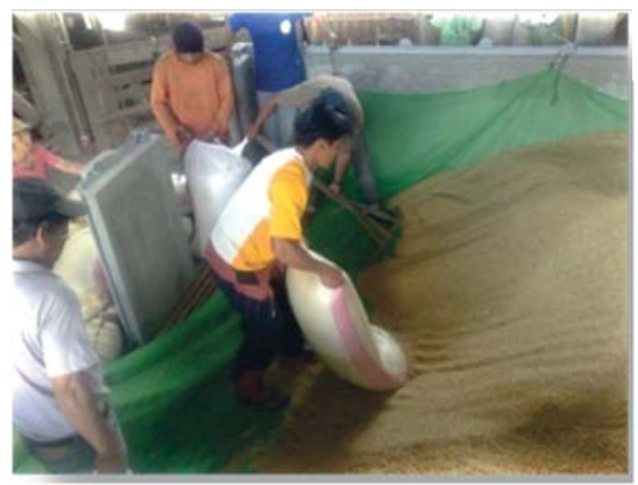

Figure 9. Grain loading training.

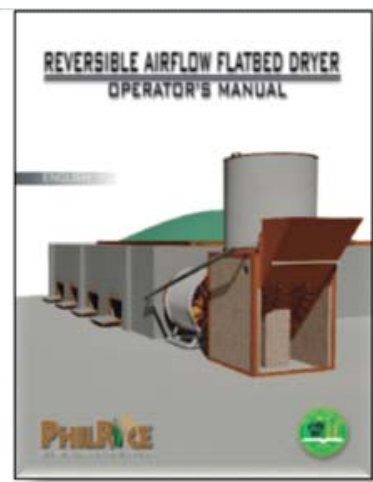

Figure 10. Operator's manual. 
Table 3. Reversible airflow flatbed dryers installed in the Philippines.

\begin{tabular}{lcc}
\hline \multicolumn{1}{c}{ Location } & $\begin{array}{c}\text { No. of } \\
\text { Units }\end{array}$ & Capacity, ton per batch \\
\hline Philrice station & 2 & 10 and 8 \\
CES $\quad$ Isabela & 1 & 8 \\
$\quad$ Los Baños & 1 & 4 \\
$\quad$ Negros & 2 & 8 \\
$\quad$ Agusan & 2 & 8 \\
$\quad$ Midsayap & 2 & 8 \\
$\quad$ CMU & 3 & 8 \\
Privately owned & & 8 \\
$\quad$ Diffun, Quirino & 1 & 8 \\
$\quad$ Cabarroguis, Quirino & 1 & 8 \\
$\quad$ Gapan, Nueva Ecija & 1 & 8 \\
$\quad$ San Antonio, & 1 & \\
Ecija Nueva $\quad$ & 1 & 4 \\
Bongabon, Nueva Ecija & & 4 \\
Community owned & & \\
$\quad$ Impasugong, Bukidnon & 2 & \\
$\quad$ Malaybalay, Bukidnon & 1 &
\end{tabular}

\section{CONCLUSIONS AND RECOMMENDATIONS}

The reversible drying technology makes it possible to achieve uniform drying at double the drying depth of the conventional flatbed dryer: thereby eliminating mixing of the grains. The $1 \%$ moisture gradient obtained at a drying depth of $60 \mathrm{~cm}$ was well below the $2 \%$ maximum limit set by PAES standards (PAES 201:2000).

The cylindrical combustion chamber with fly ash separator eliminated the problem of soot or blackening of the grains, as observed in the conventional flatbed dryers.

Economic analysis and experiences of initial adoptors of the technology indicate that even with the high investment cost of the reversible dryer, it is a viable option for custom drying with a break-even point of 53 drying batches per year, with a payback period of less than 3 years.

Further research is needed to simplify and optimize some components such as the blower in order to reduce power requirement.

Linkage with manufacturers and the private sector is a must in order to speed up diffusion of the technology to the countryside. 
Development and Promotion of the Reversible Airflow Flatbed Dryer

\section{REFERENCES}

GAGELONIA, E.C., MARTINEZ, R., and D. ALOJADO. 2013. Mechanized drying of paddy: an industry concern. Paper presented during the Asia Rice Foundation Annual Rice Forum. Bureau of Soils and Water Management Bldg., Quezon City, 22 November 2013.

HIEN, P.H. 2010. Harvesting and drying of rice in Vietnam. In: Bong BB, Bo $N V$, Buи BC (eds) Vietnam Fifty Years of Research and Development. Agriculture Publishing House, Hanoi. pp.361-380.

HIEN, P.H., TAM, N.H. and N.V.XUAN. 2003. Study on the reversal timing for the SRA reversible dryer. Paper presented at the Seminar on "Agricultural Engineering and Agro-products Processing Towards Mechanization and Modernization in Rural Areas". Nong-Lam University, Ho Chi Minh City. 11-12 December 2003.

KUIZON, P. 1995. Rice husk furnace and reversible airflow grain dryer. In: Champ BR, Highley E, Johnson GI (eds) Grain Drying in Asia. ACIAR Proceedings No. 71.pp. 356-359.

PAES 201:2000. Agricultural Machinery - Heated-Air Mechanical Grain Dryer - Specifications. Philippine Agricultural Engineering Standards, Vol. 1.pp. B-1 - B-8.

PAES 202:2000. Agricultural Machinery - Heated-Air Mechanical Grain Dryer - Methods of Test. Philippine Agricultural Engineering Standards, Vol. 1. pp. B-12 - B-36.

PCARRD. 2009. Agricultural Mechanization in the Philippines. PCARRD Book Series No. 179/2009.

VINH, L. Q. 2011. Comparative Study of the Performance of the Reversible Airflow Dryer and the Conventional Flatbed Dryer. (MSc thesis), Cental Luzon State University, Nueva Ecija, Philippines. 